\title{
O ESTÁGIO COM PESQUISA: UM OLHAR SOBRE O PROCESSO ENSINAR/APRENDER
}

Lucimar Gracia Ferreira ${ }^{1}$

D https://orcid.org/0000-0002-2152-735X

Roselane Duarte Ferraz ${ }^{2}$

https://orcid.org/0000-0003-1731-0120

Resumo: Este artigo é originado de um processo de aprendizagem referente ao Estágio Supervisionado em Educação Infantil. Teve como objetivo analisar a contribuição do estágio supervisionado articulado com a pesquisa, para formação do futuro profissional pedagogo. Ao discutir o estágio e o processo investigativo neste campo de estudo, foi possível realizar reflexões sobre os aspectos positivos em desenvolver essa estratégia de trabalho, considerando os desafios que foram enfrentados nesta experiência formativa. Desse modo, a pesquisa se deu em torno do tema do projeto de intervenção do estágio que remetia às relações étnico-raciais. Assim, as narrativas da estagiária-pesquisadora configuraram corpus deste artigo. Ressaltamos o quanto essa perspectiva de formação - estágio com pesquisa - é desafiante para os estagiários, exigindo não só do graduando, mas principalmente, da formação, a criação de condições para que se efetive um processo formativo, conduzindo estes futuros profissionais a uma perspectiva diferenciada sobre ensino, aprendizagem, democratização da educação e emancipação social.

Palavras-chave: estágio supervisionado; pesquisa; desafios; formação docente.

1Doutoranda em Educação da Universidade Federal da Bahia (UFBA). E-mail: lucimargracia@hotmail.com.

2 Professora Adjunta da Universidade Estadual do Sudoeste da Bahia (UESB). Doutora em Educação pela Universidade Federal de Pernambuco (UFPE). E-mail: rosedferraz2@gmail.com. 


\section{THE INTERNSHIP WITH RESEARCH: A LOOK AT THE TEACHING/LEARNING PROCESS}

Abstract: This article comes from a learning process related to the Supervised Internship in Early Childhood Education. It aimed to analyze the contribution of the supervised internship articulated with research, for the formation of the future professional educator. By discussing the internship and the investigative process in this field of study, it was possible to reflect on the positive aspects of developing this work strategy, considering the challenges that were faced in this formative experience. Thus, the research was based on the theme of the internship intervention project, which referred to ethno-racial relationships. Thus, the narratives of the trainee-researcher constituted the corpus of this article. We emphasize how this perspective of training - internship with research - is challenging for the trainees, demanding not only from the student, but mainly, from the training, the creation of conditions for a formative process to take place, leading these future professionals to a different perspective on teaching, learning, democratization of education and social emancipation.

Keywords: supervised internship; research; challenges; teacher training.

\section{LAS PRÁCTICAS CON LA INVESTIGACIÓN: UNA MIRADA AL PROCESO DE ENSEÑANZA/APRENDIZAJE}

Resumen: Este artículo se origina a partir de un proceso de aprendizaje relacionado con las Prácticas Supervisadas en Educación Infantil. Su objetivo es analizar la contribución de las prácticas supervisadas articuladas con la investigación, para la formación del futuro profesional de la pedagogía. Al hablar de la pasantía y del proceso investigativo en este campo de estudio, se pudo reflexionar sobre los aspectos positivos en el desarrollo de esta estrategia de trabajo, considerando los desafíos que se enfrentaron en esta experiencia formativa. Así, la investigación se basó en el tema del proyecto de intervención de las prácticas que se refería a las relaciones etno-raciales. Así pues, las narraciones del investigador en prácticas constituyeron el corpus de este artículo. Destacamos cómo esta perspectiva de formación -pasantía con investigación- es desafiante para los pasantes, requiriendo no sólo del graduado, sino principalmente, de la formación, la creación de condiciones para que se produzca un proceso formativo que lleve a estos futuros profesionales a una perspectiva diferente sobre la enseñanza, el aprendizaje, la democratización de la educación y la emancipación social.

Palabras clave: prácticas supervisadas; investigación; desafíos; formación del profesorado. 


\section{Introdução}

Este trabalho resulta de uma experiência de pesquisa, realizada no estágio em Educação Infantil, do curso de Pedagogia de uma Instituição do Ensino Superior na Bahia. Neste viés, o estágio nos proporcionou o desafio de adentrar o espaço da escola como campo de pesquisa, reconfigurando o tradicional modelo de estágio tecnicista e ressignificando as vivências e reflexões sobre a função do professor da Educação Básica.

A perspectiva de articular o estágio com a pesquisa fundamentou-se no entendimento de que ao investir na formação de professores, a universidade deve não só priorizar o estudo sobre o ensino, mas voltar-se, também, para a formação do pesquisador das questões que interferem na educação (GHEDIN; OLIVEIRA; ALMEIDA, 2015).

Imbuídos desse propósito, o estágio/pesquisa ocorreu no espaço da creche e, neste contexto, o foco estava direcionado para a compreensão do papel do professor (FERNANDES, 2007) frente à questão étnico-racial. Nesta perspectiva, consideramos importante refletir a respeito das demandas e divergências referentes à diversidade étnico-racial e cultural (CAVALLEIRO, 1999, 2000; BRASIL, 1996, 2004) vivenciadas pelos sujeitos da relação ensino-aprendizagem, no contexto da Educação Infantil, observando formação do profissional que se encontra, diariamente, mediando estas relações.

A partir deste cenário formativo, o presente artigo busca analisar a contribuição do estágio supervisionado articulado com a pesquisa, para formação do futuro profissional pedagogo. Para tanto, foram realizadas reflexões sobre os aspectos positivos em desenvolver essa estratégia de trabalho, considerando os desafios que foram enfrentados nesse campo de conhecimento.

Essas reflexões estarão, primeiramente, embasadas na ideia do estágio como um campo de formação e construção de conhecimento, em que inter-relacionam as dimensões da prática pedagógica, considerando seu potencial formativo na constituição da identidade docente e, visualizando a pesquisa como eixo articulador na relação teoria e prática. Em seguida, a partir da experiência de realizar o estágio 
com pesquisa, apresenta-se discussões e análises das contribuições do estágio articulado com pesquisa, na formação do futuro profissional da docência.

\section{O Estágio Supervisionado com pesquisa: espaço de formação docente}

O estágio supervisionado na formação inicial de professores, em muitas situações, representa o primeiro contato do graduando com o seu futuro campo de trabalho. Assim, fomenta diversas expectativas, sobretudo, considerando a relação entre teoria e prática. Algo que, historicamente, tem sido problematizado por diferentes estudos acadêmicos.

A literatura nos possibilita compreender o estágio supervisionado como um campo formativo em que inter-relacionam as dimensões da prática pedagógica e, particularmente, os elementos estruturantes da prática docente. Neste aspecto, Lima (2008, p. 198), assume a defesa deste componente curricular como:

[...] espaço de aprendizagem da profissão docente e de construção da identidade profissional, que permeia as outras disciplinas da formação, no projeto pedagógico dos cursos de formação, mas é o lócus da sistematização da pesquisa sobre a prática, no papel de realizar a síntese e a reflexão das vivências efetivadas.

Sendo assim, o estágio destaca-se pelo seu potencial formativo na construção da docência como identidade profissional, exigindo, para tanto, articulação entre os demais componentes curriculares, bem como, a inter-relação com as instituições da educação básica, materializada no projeto pedagógico dos cursos de formação de professores. Isso significa ultrapassar os limites de, apenas, dominar técnicas para aproximar-se da complexa construção identitária, indissociável das experiências sociais pertinentes ao campo de atuação da docência (FERREIRA; FERRAZ, 2021).

Para Almeida e Pimenta (2014), o estágio constitui um processo formativo que proporciona aproximações com a instituição de ensino, afunilando para as práticas pedagógicas e para as relações entre alunos e professores. Assim, possibilita a compreensão sobre o ensino e a aprendizagem, tomando como referência o campo de atuação do futuro profissional da docência.

Também, pensando no estágio como um campo fomentador da articulação entre a teoria e prática, Marques (2018, p, 119), considera que: 
Ainda que o estágio não deva ser concebido como o único espaço no qual se vislumbre a possibilidade de articulação teoria-prática nos processos de formação inicial acadêmica de professores, ele se constitui como espaço privilegiado na qual essa articulação é favorecida.

Essas concepções trazem uma complexidade no entendimento acerca do estágio que superam as várias facetas atribuídas a esta categoria, tais como a perspectiva de ser concretizado através da imitação de modelos ou como instrumentalização da prática. Além disso, indicam a necessidade de uma estreita articulação entre teoria e prática, gerando ressignificações na organização e realização dos estágios e, consequentemente, reconfigurações curriculares nos cursos de formação de professores, pois o estágio nestes velhos formatos não tem proporcionado:

Contribuições para análise da prática docente, nem mesmo de novas propostas curriculares para os cursos de formação de professores e não tem conseguido formar uma cultura docente que consiga superar aquela cultura escolar que ainda carrega muitos vícios de uma perspectiva tecnicista da educação (GHEDIN; OLIVEIRA; ALMEIDA, 2015, p. 39).

Diante deste contexto, nos últimos anos, observamos estudos (PIMENTA; LIMA, 2011; GHEDIN; OLIVEIRA; ALMEIDA, 2015; FERREIRA; FERRAZ, 2022) concentrando esforços na defesa da constituição de estágio supervisionado tendo a pesquisa como eixo articulador da teoria e prática. Nestes trabalhos, predomina o argumento de que o estágio vinculado à investigação poderá contribuir para a "formação do estagiário como futuro professor e futuro pesquisador da área" (ALMEIDA; PIMENTA, 2014, p. 32).

Estes estudos promovem uma mobilização com o foco de ressignificar as práticas de estágio e pesquisa, no campo da formação de professores. E, consequentemente, reconfigurar o perfil do futuro profissional da educação, não mais restrito ao domínio do ensino, mas com habilidades para promover pesquisas que possam contribuir no entendimento das práticas pedagógicas que embasam seu campo de trabalho, compreendendo os elementos e aspectos que condicionam o seu desenvolvimento, objetivando a transformação. 
Para Ghedin, Oliveira e Almeida (2015, p. 124), o estágio pode possibilitar ao estagiário um contato mais "estreito com a pesquisa, [...] desenvolvendo postura de pesquisador a partir das situações observadas no campo de estágio, elaborando projetos de pesquisa que lhes permitam compreender a realidade em que estão inseridos".

Vincular estágio à pesquisa cria-se um campo fértil de possibilidades formativas, pois uma área retroalimenta a outra. Enquanto o estágio aproxima o sujeito do seu campo de atuação, a pesquisa problematiza esse contexto, fomentando reflexões a respeito da realidade educacional e, consequentemente, possibilitando ações intervencionistas respaldadas no diálogo crítico e reflexivo entre teoria e prática (MAUAD; FREITAS, 2021).

Para Pimenta e Lima (2011, p. 46), a pesquisa vinculada ao estágio configura-se em duas possibilidades de formação. Neste sentido, as autoras afirmam que, por um lado possibilita a:

\begin{abstract}
Mobilização de pesquisas que permitam a ampliação e análise dos contextos onde os estágios se realizam; por outro lado, e em especial, se traduz na possibilidade de os estagiários desenvolverem postura e habilidades de pesquisador a partir das situações de estágio, elaborando projetos que lhe permitam ao mesmo tempo compreender e problematizar as situações que observam.
\end{abstract}

Esta compreensão desmistifica a ideia de conceber a experiência do estágio como a reprodução de técnicas e conhecimentos externos aos problemas e demandas próprias daquele cotidiano escolar, como um contexto que deveria ser aplicado aquilo que foi pré-estabelecido pelo curso de formação docente. Abre espaço para a construção do conhecimento, a partir do aprofundamento teórico que o objeto de estudo exigiu, confrontando com os dados apresentados da realidade investigada (idem, 2011).

Pelas argumentações observadas, consideramos pertinente o investimento em tomar a pesquisa como estratégia didática vinculada ao estágio, por possibilitar a aprendizagem por meio da problematização, avaliação, contextualização do campo de trabalho dos futuros profissionais da docência. Para isso, requer das instituições superiores de ensino uma revisão das suas propostas pedagógicas, observando o quanto os projetos de curso estão, de fato, superando a fragmentação dos 
conhecimentos produzidos nesta área, com o intuito de fomentar de práticas pedagógicas mais democráticas, no acesso e produção dos saberes (MARQUES, 2018).

\section{Aprender-ensinar com a pesquisa}

São vários os desafios encontrados ao iniciar um estágio supervisionado, pois, envolvem, além da vivência do contexto da sala de aula, também, organização e planejamento para seu desenvolvimento. Dessa forma, o estágio supervisionado, realizado com pesquisa, foi proposto pelo Estágio na Educação Infantil, do Curso de Pedagogia, de uma Instituição de Ensino Superior pública da Bahia. Realizado no espaço de uma Creche, localizada num bairro periférico, de um município do interior da Bahia. Neste contexto, foi pertinente aproximação com o campo de estágio, instituição em um bairro distante da localidade residencial da estagiária, o qual não conhecia. Esse primeiro contato foi primordial para aproximar das dimensões que configuram a instituição de ensino, perceber as relações e as intencionalidades constituídas nesta etapa de ensino.

A orientação no Estágio teve como proposta a elaboração de um projeto sobre um tema pertinente à realidade da instituição. Percebemos, nos primeiros contatos, que as questões étnico-raciais eram significativas, pois observamos que, embora a instituição atendesse a crianças majoritariamente negras, as proposições didáticas não faziam referências a este tipo de discussão. Assim, resolvemos trazer para a educação infantil, o projeto de intervenção que dialogasse com a temática étnicoracial.

Nessa perspectiva, em um primeiro momento, foram vivenciadas atividades de ensino, realizadas com os alunos, tendo o computador como ferramenta metodológica para mostrar algumas crianças (dos dois sexos), duas de cada turma (referente a quatro turmas), imagens de personagens de desenhos animados e bonecas (negras e brancas). Embora este não seja o foco na discussão deste artigo, observamos a pertinência dessa atividade para o processo de aprender-ensinar pela pesquisa, pois a intencionalidade era perceber, pelo viés da linguagem fílmica, como os alunos se aproximavam dessa temática.

Nessa atividade (filmada em vídeo), participaram 3 meninos negros e 2 meninos brancos; ainda, 3 meninas negras, e 1 menina branca. No percurso das ações, 
observamos que a maioria das crianças negras e brancas optaram, majoritariamente, pelos personagens e bonecas brancas. Isso possibilitou conhecer as crianças e suas preferências relacionadas à cor/raça e como estas, possivelmente se percebiam na sociedade. Foi perceptível como as crianças vêm incorporando um discurso estigmatizado, o preconceito de si mesmo (alguns deles eram negras) por escolher as imagens/bonecas brancas como superiores. Conforme narrativa da estagiáriapesquisadora:

\begin{abstract}
Estagiar no espaço da creche me fez crescer muito, eram só crianças de até três anos e 11 meses, mas que já tinham estigmas relacionados a cor e a raça. Ao iniciar as atividades de estágios, principalmente, esta realizada com os personagens dos desenhos infantis e as bonecas, fiquei assustada com as respostas que as crianças deram, porque eram apenas crianças, mas foi perceptível que elas já tinham uma imagem de si e do mundo. Ao mostrar as imagens dos desenhos animados para um menino negro (Branca de Neve/Chapeuzinho Vermelho, uma branca e uma negra), e, ao ser questionado qual era a cor da pele delas, se referiu a negra como "marrom" e a branca como "branca". Outra criança negra, ao ser indagada sobre a cor da pele dos personagens de desenho, se refere a todas as imagens de cor negra como "brava".
\end{abstract}

Os resultados dessa atividade com as crianças coadunam com os resultados do da pesquisa de Souza (2016). Entretanto, ser professor não é e nunca foi tarefa fácil, principalmente, quando é preciso trabalhar com temas da contemporaneidade, considerados tabus pela sociedade. É necessário ter conhecimentos e saberes para saber conduzir situações-problemas e, ao mesmo tempo, ensinar de maneira coerente para que os alunos possam levar essas aprendizagens para sua vida pessoal e social. Vai exigir também do professor uma postura reflexiva com uma visão de mundo ampla, se valendo de estratégias sistemáticas para este ensino.

Desse modo, a estagiária-pesquisadora foi impactada pelos acontecimentos cotidianos das atividades de estágio e nesse processo foi se formando, constituindo um entendimento de que tornar-se professor é uma atividade complexa. E, neste campo, a relação estágio-pesquisa desencadeou releituras do percurso formativo. Segundo Ferraz (2020), a problematização das questões que circundam as ações dos professores e o diálogo com as teorias contribuirão para ressignificar as situações de ensino-aprendizagem desses futuros profissionais. Assim, “o estágio fomenta a investigação, a problematização, o estudo e o diálogo teórico-prático para 
compreender as dimensões que configuram o processo do ensino e da aprendizagem" (idem, p. 06).

A partir de então, após as atividades realizadas com as crianças, houve a necessidade de aprofundar no processo investigativo, realizando entrevistas com as quatro professoras, para conhecer quais os saberes/informações elas haviam construídos e faziam parte do seu repertório sobre o tema do projeto de intervenção.

Quadro: Dados da entrevista com as professoras

\begin{tabular}{|c|c|c|c|}
\hline & $\begin{array}{l}\text { Conhecimento da Lei } \\
10.639 / 03\end{array}$ & $\begin{array}{l}\text { Como mediam o tema } \\
\text { junto às ações pedagógicas } \\
\text { no cotidiano escolar }\end{array}$ & $\begin{array}{l}\text { Relatar } \\
\text { acontecimento na sala de } \\
\text { aula que aponta para o } \\
\text { preconceito racial }\end{array}$ \\
\hline Professora 1 & $\begin{array}{l}\text { Só se der um apanhado } \\
\text { aí; Professora. }\end{array}$ & $\begin{array}{l}\text { A gente procura ver o } \\
\text { vivencialmente da criança, } \\
\text { contamos historinhas da } \\
\text { menina bonita do laço de } \\
\text { fita e o patinho feio. }\end{array}$ & Sobre cor nunca teve. \\
\hline Professora 2 & $\begin{array}{l}\text { Não, posso até saber, mas } \\
\text { de número, não lembro. }\end{array}$ & $\begin{array}{l}\text { Pretendemos trabalhar } \\
\text { com a moreninha bonita } \\
\text { do laço de fita. }\end{array}$ & $\begin{array}{l}\text { - Já, não nesta escola, } \\
\text { mas, em outra já, aqui } \\
\text { nunca teve. }\end{array}$ \\
\hline Professora 3 & Não conheço. & $\begin{array}{l}\text { A gente trabalha o conto } \\
\text { inclusive aquela do laço de } \\
\text { fita e a música de Aline } \\
\text { Barros que fala um é } \\
\text { diferente do outro. }\end{array}$ & Em relação à cor não. \\
\hline Professora 4 & $\begin{array}{l}\text { Não, só se você citar aí } \\
\text { para mim. }\end{array}$ & $\begin{array}{l}\text { No momento não temos } \\
\text { trabalhado sobre isso. } \\
\text { Essas questões raciais eles } \\
\text { são muito pequeninos eles } \\
\text { não têm distinção disto } \\
\text { pelo ao menos na minha } \\
\text { sala não. }\end{array}$ & Na minha sala nunca teve \\
\hline
\end{tabular}

Foi apontado que, nesse contexto de ensino, as ações pedagógicas não são voltadas para trabalhar as questões das Relações Étnico-Raciais. Os argumentos apresentados no quadro acima revelam indícios de pouco conhecimento sobre o tema. Essa constatação fomenta questionar como esses profissionais iriam trabalhar as relações pedagógicas no campo de uma lei que desconheciam? Essa problemática fez parte do contexto de aprendizagem da estagiária-pesquisadora.

Diante das especificidades das aprendizagens do estágio no ambiente da creche e das aulas que envolveu o cuidar-educar, compreendi a 
importância desse binômio que é indissociável e, próprio do pedagogo, sujeito habilitado para atuar neste espaço. Percebi que como professora, é preciso também que eu tenha conhecimentos e construir saberes, para que assim, possa trabalhar questões que conheço, pois, muitos deles são necessários para a vivência no mundo, nossa e dos alunos, como o tema diversidade, pois é importante para se sustentar na sociedade, e por isso, é fundamental que faça parte do repertório de saberes docente. Somente compreendi isso, quando estive inserida no contexto do estágio e, a questão das relações étnico-raciais é um desses saberes, que, visivelmente, não fazia parte dos saberes das professoras, mas que era necessário para que elas ensinassem e voltassem as ações pedagógicas para este tema (Estagiária-pesquisadora).

A quem cabe a responsabilidade de remeter a construção de conhecimentos sobre os temas contemporâneos da educação? A Universidade? Ao estudante em formação? Ao professor em atuação? É bem verdade que a universidade tem sua própria estrutura curricular, agregando componentes da Educação Especial e Inclusiva, Relação Étnico-Racial e questão de Gênero como temas comuns da licenciatura na formação de professores. Entende-se que ela precisa ter em sua base curricular estes conhecimentos, essas disciplinas. Construir esses alicerces e aprofundar é, também, responsabilidade do estudante em formação, bem como, dos professores em atuação. Pois, não cabe esperar somente pela universidade ou pelo que ela pode te proporcionar. É necessário buscar em outros lugares e espaços esses conhecimentos.

Refletindo sobre esse contexto de estágio e pesquisa e as aprendizagens relacionadas a ensinar-aprender, ficou evidente que, a partir de suas vivências no mundo, as crianças contruíram uma visão estigmatizada de si. Neste âmbito, a creche em sua organização pedagógica e seus sujeitos apresentavam dificuldades em proporcionar uma aprendizagem que possa reconfigurar essas concepções, considerando o pouco domínio que professoras possuíam sobre essa problemática. Então, o conhecimento apresentado por esses alunos refletia, por um lado, a ausência das ações pedagógicas daquele ambiente para o trabalho com a diversidade e as relações étnico-raciais. Assim, os alunos tendiam a reproduzir aspectos apreendidos em outros espaços sociais.

Como aprendizagem pela pesquisa, foi perceptível que não devemos subestimar a inteligência das crianças, elas nunca são pequenas demais para 
aprenderem. Desse modo, a questão do pertencimento, consciência de classe/raça que remetem a diversidade deve ser tema recorrente nos espaços escolares ${ }^{3}$.

Estes resultados da pesquisa foram relevantes para mim, pois contribuiram para ampliar minha visão como professora, como processo de investigação, de estudo de caso e como situaçãoproblema. As respostas das crianças e das professoras agregou valores ao meu processo formativo e crescimento profissional, através da visão do cotidiano da escola, pois, esta, não é só feito de lápis, caderno, borracha, lousa; a escola não é só feita de conteúdo; é feita também de sentimentos e de relações sociais e afetivas (Estagiária-pesquisadora).

A fala da estagiária comunga com as percepções apresentadas por Ferreira e Ferraz (2022) ao ressaltar que a realização do estágio com pesquisa fomenta o pensamento crítico sobre as práticas pedagógicas, proporcionando ao estagiário processos de aprendizagem e de transformações a respeito dos problemas identificados pela investigação.

Nesse contexto de aprendizagens do estágio, fez parte, ainda, um último momento na escola, em que todas as professoras foram convidadas para receber o feedback da pesquisa, tanto delas, quanto dos alunos. Foi montada uma sala com um projetor e selecionadas as cenas filmadas com as crianças, que foram assistidas pelas professoras. Também, foram cruzadas com essas cenas, respostas fornecidas pelas professoras na entrevista. Esse se mostrou um momento de surpresas para as professoras, pois, elas não tinham o conhecimento de que as crianças estigmatizavam o negro, mesmo sem saber o seu significado e reproduzindo, aquilo que os adultos e seus pares pensam a respeito disso. Esse cenário se mostrou profícuo de aprendizagens e, extremamente, formativo, em que o estágio se consolidou de um modo muito peculiar com pesquisa. Desse modo:

\footnotetext{
${ }^{3}$ Semelhante a isso, temos o texto de Moysés, Geraldi e Collares (2002) que narra a história de Betina, uma criança que tem conhecimentos, para além daquilo que é ensinado na escola e da série em que e encontra, mas que os omite para que a professora saiba que ela já sabe e fique triste. Ou seja, Betina não estava autorizada a conhecer (mesmo já conhecendo) se a escola ainda não tinha ensinado. Este texto retrata a realidade de que o ato de conhecer dos alunos não é refletido.
} 
Após o momento de atividades com os alunos e da entrevista com as professoras, foi realizada a autoconfrontação cruzada, em que se reuniu as quatro professoras para assistir as filmagens das atividades realizadas com as crianças. Cada cena assistida era um momento de surpresa, as professoras viam seus alunos fazerem escolhas que remetiam a uma interpretação preconceituosa e de não pertencimento. Elas viam que aquilo que falaram na entrevista não coadunam com o que os alunos faziam nas cenas. Percebi que essas questões precisam ser trabalhadas na escola, discutidas, problematizadas, aprendidas lá. A escola não tem o direito de estabelecer tempos, datas para as crianças aprenderem. Elas aprendem em qualquer tempo e lugar e se a escola ou a família não ensinarem, o mundo vai fazer isso, o que pode ocorrer da pior forma. Então, esse estágio, o primeiro que estou realizando nessa graduação, já me proporcionou muitas reflexões formativas de como posso ser professora, de como posso conduzir meu ensino, do que devo priorizar para abordar em sala de aula. É a minha formação e aprendi muito nesse processo de investigação e percebi a diferença disso para outros contextos de formação (Estagiária-pesquisadora).

Pensando nas contribuições do estágio articulado à pesquisa no processo formativo dos graduandos, constatamos que as observações e argumentações apresentadas pela estagiária-pesquisadora vão dialogar com as expectativas de Marques (2018, p. 119), quando a autora considera que o estágio com pesquisa fomenta a "construção de leituras críticas sobre o que observa". Neste caso, a estagiária-pesquisadora vai expor a contradição existente entre aquilo que as professoras consideram como ideal de ensino e aprendizagem para o estudo da Lei 10.639/03 e o observado nas aulas, demonstrando a informalidade e superficialidade do tema trabalhado, junto às crianças.

Nesta experiência de vivenciar o estágio com pesquisa, Marques (idem, p.119), vai destacar, também, a possibilidade de "construção de um habitus de pesquisa e investigação sobre a realidade (ao compreender a importância da reflexão sistemática sobre a prática, da inquietação, da problematização do real)". Os detalhes identificados pela estagiária pesquisadora nas imagens como adereços ilustrativos, nos corredores e salas de aula, representando as crianças negras e brancas, bem como o diálogo teórico estabelecidos com pesquisadores, na percepção da necessidade de assegurar um planejamento coletivo e sistemático das práticas pedagógicas, nos dão indícios desse processo de refinamento investigativo, da curiosidade científica em problematizar e compreender este contexto de ensino e aprendizagem.

\section{Diálogos experiencias na realização do estágio com pesquisa}


Na licenciatura em Pedagogia da Universidade Estadual do Sudoeste da Bahia UESB/Campus de Itapetinga, o estágio é realizado a partir do terceiro ano de formação. Inicia no $6^{0}$ semestre com o Estágio I - Educação Infantil, depois 7ํㅜ semestre com Estágio II - Ensino Fundamental - Séries Iniciais, e finalizando com os estágios III - Estágio em Populações Diferenciadas e IV- Estágio em Gestão. Nestes estágios são desenvolvidas atividades de investigação/pesquisa, regência de classe, participação em seminários, intervenção pedagógica em instituições formais e não formais de ensino.

Tratando, especificamente, do Estágio I - Educação Infantil é importante esclarecer que estes são organizados a partir da perspectiva do estágio com pesquisa, materializado por procedimentos que orientam no desenvolvimento inicial da observação da escola campo de estágio, considerando suas realidades e especificidades, com o objetivo dos estagiários elaboraram e desenvolveram um projeto de pesquisa, definido a temática, proveniente desse processo de observação.

Segundo Ghedin, Oliveira e Almeida (2015) desenvolver estudos no campo da educação convida o sujeito-pesquisador a imergir na realidade pesquisada, tornandose, também, objeto de pesquisa. Assim, construímos esse eixo analítico, a partir da perspectiva da aluna-estagiária, considerando seus relatos, suas reflexões, originárias do relatório final, das vivências e experiências em articular o estágio com pesquisa.

Um aspecto positivo em desenvolver o estágio com pesquisa encontra-se no processo de se estabelecer, por meio da investigação, problematização e reflexão, o diálogo entre o contexto de trabalho com as diversas áreas de conhecimento (FERREIRA; FERRAZ, 2022). Conforme a fala abaixo:

A formação docente é necessária para compreendermos a prática pedagógica e desenvolvermos o trabalho do professor. Nas licenciaturas, faz parte dessa formação, os estágios supervisionados em docência, onde há aprendizagens constantes. 0 estágio é de fundamental importância para a formação docente nos cursos de licenciatura. Através do estágio são proporcionadas aprendizagens contínuas em observar a sala de aula, planejar, errar e fazer possíveis correções; conhecer a rotina da instituição, ter uma visão crítica e reflexiva sobre sua atuação e a do outro em sala de aula (Estagiáriapesquisadora). 
Ao pesquisar sobre as práticas dos professores frente às questões étnico-raciais na Educação Infantil, a estagiária relata a necessidade de dialogar com os estudos voltados para o tema, no intuito de compreender/analisar as posições tomadas pelos docentes frente aos estudos da Lei 10.639/03 e ao planejamento voltado para o debate e a formação das crianças, diante do enfrentamento das práticas racistas. Este processo fomentou confronto crítico e reflexivo entre as teorias estudadas e as práticas observadas.

O estágio como um dos principais espaços para o estudante realizar pesquisas pode constituir-se no primeiro passo para a construção de sua identidade de professor-pesquisador, pois neste momento ele pode adquirir postura e habilidades que propiciem uma leitura crítica do contexto educativo a partir da problematização das situações que o observem (GHEDIN; OLIVEIRA; ALMEIDA, 2015, p. 241).

Também foi possível observar o ganho formativo da estagiária-pesquisadora ao tomar como objeto de estudo uma temática originária das demandas problematizadas na escola campo de estágio. Não impondo, ao contexto escolar, um objeto investigativo nascido das discussões universitárias. Conforme estagiária: "a questão da diversidade vem sendo muito debatida, e as escolas públicas são carentes desse debate, portanto, optamos em discutir as relações étnico-raciais neste estágio". Colocando como desafio para si e para a escola, a busca de respostas para os problemas identificados.

Partir do real - em toda sua complexidade -, selecionar um foco, elaborar um problema e procurar investigá-lo requer a superação de uma postura passiva e receptora rumo à construção de uma autonomia intelectual que implica escolher um tema, pesquisar e elaborar conhecimentos sobre a questão discutida, o que não é tarefa simples (MARQUES, 2018, p. 122).

Além disso, outro aspecto importante no desenvolvimento do estágio como pesquisa foi o estabelecimento de um diálogo fundado na confiança entre estagiária e professores. Assim, "fomos muito bem recebidos na escola, fomos acompanhados a todo tempo pelo coordenador pedagógico que nos supervisionou e nos deu todas as informações necessárias. A gestora, a equipe de apoio e os professores foram muito atenciosos conosco. Gostamos muito". 
Contudo, constatamos alguns desafios para promover o desenvolvimento da proposta de estágio com pesquisa. 0 primeiro deles encontra-se na dificuldade que os graduandos têm em realizar pesquisas, pois não estão familiarizados com essa prática. Prevalecia a ausência de domínio sobre os procedimentos na elaboração do projeto, definição dos métodos e, consequentemente, na condução do processo investigativo. Desse modo:

Dialogar com o coordenador, professores, diretora e auxiliares dessa instituição sobre a existência e obrigatoriedade da Lei 10.639/03 abordando principalmente as questões étnicas raciais, nos mostrou mais uma grave deficiência em nossas escolas públicas, toda a equipe gestora não conhecia ou não se lembrava da Lei que entrou em vigor desde 2003. E consequentemente o papel do coordenador que não promovia dentro desse espaço essas reflexões (pesquisas), dentre tantas outras importantes dando continuidade a sua formação, ampliando os conhecimentos de forma considerável (Estagiáriapesquisadora).

A segunda dificuldade encontrava-se na orientação dos projetos de pesquisa, pois no âmbito do diálogo dos objetos de estudo do estágio, existia uma gama de temáticas, das quais os professores, orientadores do estágio, deveriam acompanhar, avaliar, problematizar, em diferentes campos de estágio.

E, por fim, ainda não vivenciamos uma construção coletiva da pesquisa, pois a participação e a integração escola e universidade se mostra tímida, carente de aperfeiçoamentos. E neste sentido, observando ser o estágio um campo de formação, concordamos com Ferraz e Ferreira (2021), na defesa do fortalecimento da aprendizagem colaborativa entre essas duas instâncias de formação, em um movimento de compartilhamento de saberes.

Todas essas observações nos levaram a considerar a riqueza dessa experiência pedagógica. Percebemos o crescimento formativo, ao dialogar com o nosso futuro campo de trabalho. Debruçar-se, cientificamente, sobre as demandas do cotidiano escolar despertou a necessidade de associar o desenvolvimento do trabalho pedagógico à pesquisa.

\section{Considerações Finais}

Pensar no processo de ressignificação do estágio supervisionado abarca discussões que vão dialogar com algumas estratégias pedagógicas. Neste texto, 
apresentamos um recorte de estudo, direcionado para a vinculação entre estágio e pesquisa, visualizando possibilidades de fomentar a articulação entre teoria e prática.

Concluímos, então, o quanto realizar um estágio articulado à pesquisa torna-se desafiante para os estagiários, exigindo não só do graduando, mas principalmente, da formação, a criação de condições para que se efetive um processo formativo, conduzindo estes futuros profissionais a uma perspectiva diferenciada sobre ensino, aprendizagem, democratização da educação e emancipação social.

Embora o estágio realizado tenha como foco a vinculação com a pesquisa, reconhecemos o quanto essa aproximação, ainda, é tímida diante das perspectivas apresentadas por alguns estudos (GHEDIN; OLIVEIRA; ALMEIDA, 2015; PIMENTA, 2015), que tomam como princípio o desenvolvimento de uma modalidade de estágio de natureza interdisciplinar, transdisciplinar, planejado e experienciado coletivamente, envolvendo professores universitários, estagiários e professores das escolas da educação básica em torno de objetos comuns de investigação.

Assim, consideramos importante um repensar das propostas de estágio articulado à pesquisa, no sentido de desenvolver um trabalho mais consolidado nesta área, com práticas interdisciplinares no decorrer do curso, em que os componentes curriculares possam vivenciar um diálogo conectado com a realidade das instituições da educação básica, visando apresentar proposições coerentes com as demandas investigadas nestes contextos de ensino.

Ao final desse percurso, constatamos um crescimento formativo para a estagiária-pesquisadora, pois ao familiarizar-se com os complexos caminhos que envolvem o estágio vinculado à pesquisa houve um ganho na configuração da sua identidade docente e, especialmente, na construção de bases para o desenvolvimento do perfil da professora-pesquisadora.

\section{Referências}

ALMEIDA, M. I.; PIMENTA, S. G. Centralidade do Estágio em cursos de Didática nas Licenciaturas: rupturas e ressignificações. In: ALMEIDA, M. I.; PIMENTA, S. G. (Orgs.) Estágio Supervisionado na Formação Docente: educação básica e educação de jovens e adultos. São Paulo: Cortez, 2014.

BRASIL. Lei no 9.394 de 20 de dezembro de 1996. Disponível em <http://www.planalto.gov.br/ccivil_03/leis/19394.htm>. Acesso em: 20 jan. 2017. 
BRASIL. Lei n. 10.639, de 9 de janeiro de 2003. Altera a Lei no 9.394, de 20 de dezembro de 1996, que estabelece as diretrizes e bases da educação nacional, para incluir no currículo oficial da rede de ensino a obrigatoriedade da temática "História e Cultura Afro-Brasileira e Africana", e dá outras providências, Brasília 2003. Disponível em: http://www.planalto.gov.br/ccivil_03/leis/2003/L10.639.htm. Acesso em: 20 nov. 2019.

BRASIL. Diretrizes Curriculares Nacionais para a Educação das Relações ÉtnicoRaciais e para o Ensino de História e Cultura Afro-Brasileira e Africana. Brasília, 2004. Disponível em: http://www.uel.br/projetos/leafro/pages/arquivos/DCN-s\%20\%20Educacao\%20das\%20Relacoes\%20Etnico-Raciais.pdf. Acesso em: 15 jan. 2017.

CAVALLEIRO, E. dos S. Do silêncio do lar ao silêncio escolar: racismo, preconceito e discriminação na educação infantil. São Paulo: Contexto, 2000.

CAVALLEIRO, E.S. O Processo de Socialização na Educação infantil: A Construção do Silêncio e da Submissão. Rev. Bras. Cresc. Desenv. Hum., São Paulo, 9(2), 1999.

FERREIRA, L. G; FERRAZ, R. D. 0 estágio supervisionado nas licenciaturas: a pesquisa como estratégia na ressignificação das práticas de ensino e aprendizagem. In: OLIVEIRA, C. Z. de; FARIAS, H. J. R. de. Estágio com pesquisa: propostas para a Formação Docente. Campinas, SP: Mercado das Letras, 2022, no prelo.

FERREIRA, L. G.; FERRAZ, R. D. Por trás das lentes: o estágio como campo de formação e construção da identidade profissional docente. Revista Hipótese. v. 7, n. único. p. 301-320. 2021.

FERNANDES, M. J. S. O professor coordenador pedagógico, a articulação do coletivo e as condições de trabalho docente nas escolas públicas estaduais paulistas. Afinal, o que resta a essa função? Disponível em http://coordenacaoescolagestores.mec.gov.br/ufmt/file.php/1/Cursos-AnoBase_2013/Acervo_BibliotecaS3-RE_2013. Acesso em: 06 fev. 2018.

FERRAZ, R. D.; FERREIRA, L. G. Estágio supervisionado no contexto do ensino remoto emergencial: entre a expectativa e a ressignificação. Revista de Estudos em Educação e Diversidade. v. 2, n. 4, 2021. p. 1-28. 2021. Disponível em: https://periodicos2.uesb.br/index.php/reed/article/view/8963. Acesso em: 20 ago. 2021.

FERRAZ, R. D. Estágio supervisionado na formação do pedagogo: contribuições e desafios. Revista Encantar, v. 2, p. 01-12, 1 jun. 2020. Disponível em: https://www.revistas.uneb.br/index.php/encantar/article/view/8691. Acesso em: 17 ago. 2021.

GHEDIN, E; OLIVEIRA, E. S; ALMEIDA, W. A. Estágio com pesquisa. São Paulo: Cortez, 2015.

LIMA, M. S. L. Reflexões sobre o estágio/prática de ensino na formação de professores. Revista Diálogo Educacional. Curitiba, v. 8, n. 23, p. 195-205, jan./abr. 2008. 
MARQUES, A. C. T. L. Didática e estágio na licenciatura: por que pensar o ensino com (o) pesquisa? In: AROEIRA, K. P.; S. G. P. (Orgs). Didática e estágio. 1. ed. Curitiba: Appris, 2018.

MAUAD, S.; FREITAS, L. G. de. Ensino remoto emergencial e o estágio supervisionado em educação em tempos de pandemia da covid-19. Revista de Estudos em Educação e Diversidade - REED, [S. l.], v. 2, n. 4, p. 1-27, 2021. Disponível em:

https://periodicos2.uesb.br/index.php/reed/article/view/8318. Acesso em: 25 out. 2021.

MOYSÉS, M. A. A.; GERALDI, J. W.; COLLARES, C. A. L. As aventuras do conhecer: da transmissão à interlocução. Educação \& Sociedade, ano XXIII, no 78, abr./2002. Acesso em: 08 nov. 2020. Disponível em:

https://www.scielo.br/pdf/es/v23n78/a07v2378.pdf

PIMENTA, S. G.; LIMA, M.S.L. Estágio e docência. 6. ed. São Paulo: Cortez, 2011. (Coleção Docência em Formação).

PIMENTA, S. G. 0 protagonismo da didática nos cursos de licenciatura: a didática como campo disciplinar. MARIN, A. J; PIMENTA, S. G. Didática: teoria e pesquisa. $1^{\underline{a}}$ ed. Araraquara, SP: Junqueira e Marin,2015.

SOUZA, E. Q. Crianças negras em escolas de "alma branca": um estudo sobre a diferença étnico-racial na educação infantil. Tese de Doutorado. Programa de PósGraduação em Educação. Universidade Federal de São Carlos - SP, 2016.

Recebido em: 16 abril 2021 Aceite em: 15 outubro 2021 